\title{
Effects of Crowd Size, Composition, and Noise Level On Pool Use in a Mixed-Species Penguin Colony
}

\author{
Ashley N. Edes ${ }^{1, *}$, Eli Baskir1, Karen L. Bauman', Nathasha Chandrasekharan ${ }^{2, \dagger}$, Michael Macek ${ }^{3}$, \\ and Anne Tieber ${ }^{3}$
}

${ }^{1}$ Department of Reproductive and Behavioral Sciences, Saint Louis Zoo

${ }^{2}$ Department of Biological Sciences, Western Illinois University

${ }^{\dagger}$ Current affiliation: School of Social Work, University of Minnesota-Twin Cities

${ }^{3}$ Bird Department, Saint Louis Zoo

*Corresponding author (Email: aedes@stlzoo.org)

Citation - Edes, A. N., Baskir, E., Bauman, K. L., Chandrasekharan, N., Macek, M., \& Tieber, A. (2021). Effects of crowd size, composition, and noise level on pool use in a mixed-species penguin colony. Animal Behavior and Cognition, 8(4), 507-520. https://doi.org/10.26451/abc.08.04.05.2021

\begin{abstract}
Studies on how visitors affect penguins in human care report a mixture of negative, neutral, and positive impacts on behavior and physiology. Swimming is a highly motivated behavior that may promote positive welfare in penguins. We investigated how visitor crowd size, composition, and noise levels impact pool use in a mixed-species colony housing king (Aptenodytes patagonicus; $n=20$ ), gentoo (Pygoscelis papua; $n=14$ ), and southern rockhopper (Eudyptes chrysocome; $n=24$ ) penguins. We used video and sound loggers to record if penguins were on land or in water, the number of human adults and children present, and noise levels using 5-minute scan samples from 09:00-15:00 over 36 continuous days. Data were analyzed using linear mixed models with proportion of penguins in the water as the dependent variable and crowd size, composition, and noise levels in A-weighted (dBA) and $\mathrm{C}$-weighted $(\mathrm{dBC})$ scales as independent variables. Crowd size was positively associated with pool use in gentoo penguins. Crowd composition did not predict pool use in any species. Noise levels in dBA, which is adjusted to the higher frequencies of human hearing, positively predicted pool use in southern rockhopper penguins. Noise levels in $\mathrm{dBC}$, which captures lower frequencies, did not predict pool use in any species. No evidence of negative visitor effects was observed. Instead, these results suggest visitors are a neutral stimulus to king penguins and may be enriching to gentoo and southern rockhopper penguins.
\end{abstract}

Keywords - Visitor effects, Behavior, Decibel, Welfare, Zoo

The daily presence of visitors is one of the many factors that influence the lives and wellbeing of animals in human care. Studies using behavioral and physiological measures have documented that visitors can have a range of effects on zoo-housed animals (for review, see Davey, 2007; Fernandez et al., 2009; Hosey, 2000, 2005; Sherwen \& Hemsworth, 2019). The majority of this research has been conducted in mammals, but there are some reports across avian taxa (e.g., Azevedo et al., 2012; Blanchett et al., 2020; Collins \& Marples, 2015; Downes, 2012; Nimon \& Dalziel, 1992; Rose et al., 2018, 2020; Vargas-Ashby \& Pankhurst, 2007). In birds, visitor effects have been most frequently studied in penguins. As with observations reported in the literature on how wild penguins react to human disturbances, zoo-housed penguins show a wide variety of responses to visitors.

Penguins in the wild have been described as "easily disturbed" by human activity (Simeone et al., 2002). Behavioral changes, such as increases in alarm behaviors, vigilance, and aggression, have been 
documented in response to human approaches in African (Spheniscus demersus; van Heezik \& Seddon, 1990), Magellanic (S. magellanicus; Fowler, 1999), Humboldt (S. humboldti; Ellenberg et al., 2006), gentoo (Pygoscelis papua; Holmes, 2007; Holmes et al., 2006), king (Aptenodytes patagonicus; Holmes, 2007), royal (Eudyptes schlegeli; Holmes, 2007), and snares (E. robustus; Ellenberg et al., 2012) penguins. Physiologically, human approaches can trigger elevations in heart rate in Humboldt penguins (Ellenberg et al., 2006) and glucocorticoids in yellow-eyed penguins (Megadyptes antipodes; Ellenberg et al., 2007). However, there also is evidence that humans can be minimally disruptive to wild colonies. Potential habituation to human disturbance has been reported for African (van Heezik \& Seddon, 1990), gentoo (Barbosa et al., 2013; Cobley \& Shears, 1999; Holmes et al., 2006; Lee et al., 2017; Lynch et al., 2019; Nimon et al., 1995, 1996), Magellanic (Fowler, 1999; Walker et al., 2005, 2006), Humboldt (Ellenberg et al., 2006), yellow-eyed (Ellenberg et al., 2009), emperor (A. forsteri; Burger \& Gochfeld, 2007), and king (Viblanc et al., 2012) penguins. For example, Magellanic penguins in more frequently visited colonies exhibited reduced alarm and vigilance behavior as well as lower glucocorticoids in response to approaching humans than those from undisturbed colonies (Walker et al., 2006). Similarly, disturbed vs. undisturbed yellow-eyed penguin groups had similar baseline glucocorticoid levels (Ellenberg et al., 2007).

In one of the first studies on visitor effects in zoo-housed penguins, Sherwen and colleagues suggested penguins "might be particularly fearful of humans and therefore potentially susceptible to negative effects from exposure to visitors in zoos" (Sherwen et al., 2015, p. 72). This study showed little penguins (Eudyptula minor) hid behind vegetation, spent little time swimming, and engaged in more frequent aggression, huddling, and vigilant behaviors when the zoo was open compared to closed (Chiew et al., 2019; Sherwen et al., 2015). These differences in behavior appeared to be reactions to guest proximity, as a barrier moving guests $2 \mathrm{~m}$ away from the edge of their pools returned activity patterns to levels observed when the zoo was closed (Chiew et al., 2019). At another zoo, when a viewing window was intentionally blocked, little penguins spent more time near this area and, when there, engaged in less vigilance and more preening (Chiew et al., 2020). An early study suggested increased activity levels of African and gentoo penguins with large crowd sizes indicated they were agitated or disturbed (Warren et al., 2003), although activity levels could also indicate interest or positive stimulation. Although the number of guests was not counted and the result was not significant, a more recent study reported less time spent swimming in Humboldt penguins on weekends versus weekdays, which typically have higher visitation (Fernandez et al., 2021). Together, these studies lend support to the hypothesis that penguins may be negatively impacted by visitors.

Alternatively, multiple zoo studies on penguins report neutral or even positive effects of visitors, providing possible evidence of habituation. In an early study, African penguins decreased resting behavior when their new habitat was fully opened to the public for the first time, but it is unlikely visitors had a negative impact as the birds also began performing mating behaviors and nest building during this same five-day period (Brooking \& Price, 2004). In another study, when an immersive habitat with a human swimming pool adjacent to, and with a viewing window into, a penguin pool was first opened, African penguins spent less time swimming as the number of people in the pool increased, but this association disappeared within two months (Ozella et al., 2015). Furthermore, there was no significant correlation between visitor numbers and glucocorticoids in this group (Ozella et al., 2017). Also in African penguins, offering close-up encounters did not influence behavior in the colony and several penguins voluntarily participated in these encounters multiple times (Saiyed et al., 2019). At another zoo, African penguins showed no differences in behavior or space use between when a zoo was closed for the COVID-19 pandemic and reopening (Williams et al., 2021). Two Fiordland penguins (E. pachyrhynchus) did not change their time spent out-of-sight and engaged in more pool use on days when guest numbers were higher (Fanning et al., 2020). Negative behavior by children (e.g., banging on the glass, attempting to touch the animals) did not impact pool use in Humboldt or gentoo penguins (Collins et al., 2019). Positively, Humboldt penguins spent more time swimming submerged when people were present to interact with visitors at the underwater viewing window (Condon et al., 2003). Increased time spent 
swimming was observed in gentoos between a pre-opening and a "light" opening phase (i.e., staff and a few quiet guests) of a new exhibit (Brooking \& Price, 2004). Finally, gentoo penguins showed increased pool use and behavioral diversity with higher visitor numbers (Collins et al., 2016).

While crowd size is often analyzed in visitor effect studies, crowd composition (i.e., proportion of children to adults) and noise from visitors are less frequently examined variables. Given the design of the habitat in this study, a crowd with a greater proportion of children, herein defined as the same or shorter height than the top of the pool wall, may be perceived as less threatening because they are unable to lean over the edge. Sherwen et al. (2015) suggested "looming" behavior by guests might contribute to the avoidance and fear-related behaviors observed in little penguins. Alternatively, children may be more likely to bang on the glass than adults, although a previous study demonstrated this behavior did not impact pool use in penguins (Collins et al., 2019). As colonial birds that rely heavily on acoustic communication (Aubin \& Jouventin, 1998; Jouventin et al., 1999; Jouventin \& Aubin, 2002), penguins may be particularly susceptible to auditory stress (Francis et al., 2009; Ortega, 2012), especially when housed indoors. Although Chiew and colleagues (2019) reported that behavioral changes observed in little penguins were driven by visitor behavior rather than noise levels, these penguins were housed in an outdoor habitat; as indoor habitats have significantly higher sound levels (Pelletier et al., 2020), habitat design may moderate the impacts of noise from visitors. Crowd size, composition, and noise levels are likely to be correlated as well. For example, when comparing noise levels in front of a cockatoo aviary in a control condition and in a condition with children present, the latter was more than $18 \mathrm{~dB}$ louder (Collins \& Marples, 2015).

In the wild, penguins spend substantial time foraging at sea (Collins et al., 2016; Fernandez et al., 2019; Fuller et al., 2019; Kalafut \& Kinley, 2020; Sherwen et al., 2015). As such, although penguins in zoos are not expected to spend comparable amounts of time swimming as their wild conspecifics (Marshall et al., 2016), swimming is considered a highly motivated behavior and may promote positive welfare (Chiew et al., 2019; Collins et al., 2016; Fuller et al., 2019; Marshall et al., 2016). In addition to fulfilling a behavioral need, providing a species-typical form of activity, and reducing boredom, research suggests penguins that spend more time swimming have fewer health concerns. For example, reduced swimming in penguins is a predisposing factor for bumblefoot (i.e., pododermatitis; Erlacher-Reid et al., 2012; Fernandez et al., 2019) and preening gland infections (Terio et al., 2018). Together, these have led to efforts to find environmental enrichment strategies that will increase the amount of time penguins in zoos spend swimming (Collins et al., 2019; Fernandez et al., 2019, 2021; Kalafut \& Kinley, 2020). Consequently, factors that reduce or limit pool use could compromise welfare and may need to be mitigated. Our objective was to investigate visitor effects in king, gentoo, and southern rockhopper $(E$. chrysocome) penguins housed in a mixed-species colony by examining effects of crowd size, crowd composition, and noise levels on pool use.

\section{Method}

Data were collected for 36 continuous days between June and July 2016, months that typically have the highest attendance at the Saint Louis Zoo. The Lichtenstein Penguin Cove at the Saint Louis Zoo's Penguin and Puffin Coast is a $311.2 \mathrm{~m}^{2}$ indoor habitat with an $83.28 \mathrm{~m}^{3}$ freshwater pool. The combined land surface area is $85.7 \mathrm{~m}^{2}$ and total pool surface area is $69.0 \mathrm{~m}^{2}$. The habitat has two areas separated by $1.2 \mathrm{~m}$ high Plexiglas walls that form a 3.8-4.0 $\mathrm{m}$ path for visitors through the middle (Figure 1). Penguins are able to move freely underwater between these spaces. Temperature in the habitat is consistently maintained between $45-50^{\circ} \mathrm{F}$. Lighting levels mimicked what the penguins would experience in the wild, specifically on South Georgia Island; since summer in the northern hemisphere is winter in Antarctica, lighting never reached full brightness during the day. The photoperiod remained consistent throughout the study, with 9.5-10 daylight hours beginning at 07:00. A recording of sounds mimicking wild penguin habitats played on a continual loop while staff were present. As guests could directly 
approach the edge of the pool, a zoo security person was always present when visitors were in the building in an attempt to assure that no one touched or fed the penguins.

\section{Figure 1}

Map of Lichtenstein Penguin Cove Inside Saint Louis Zoo's Penguin and Puffin Coast

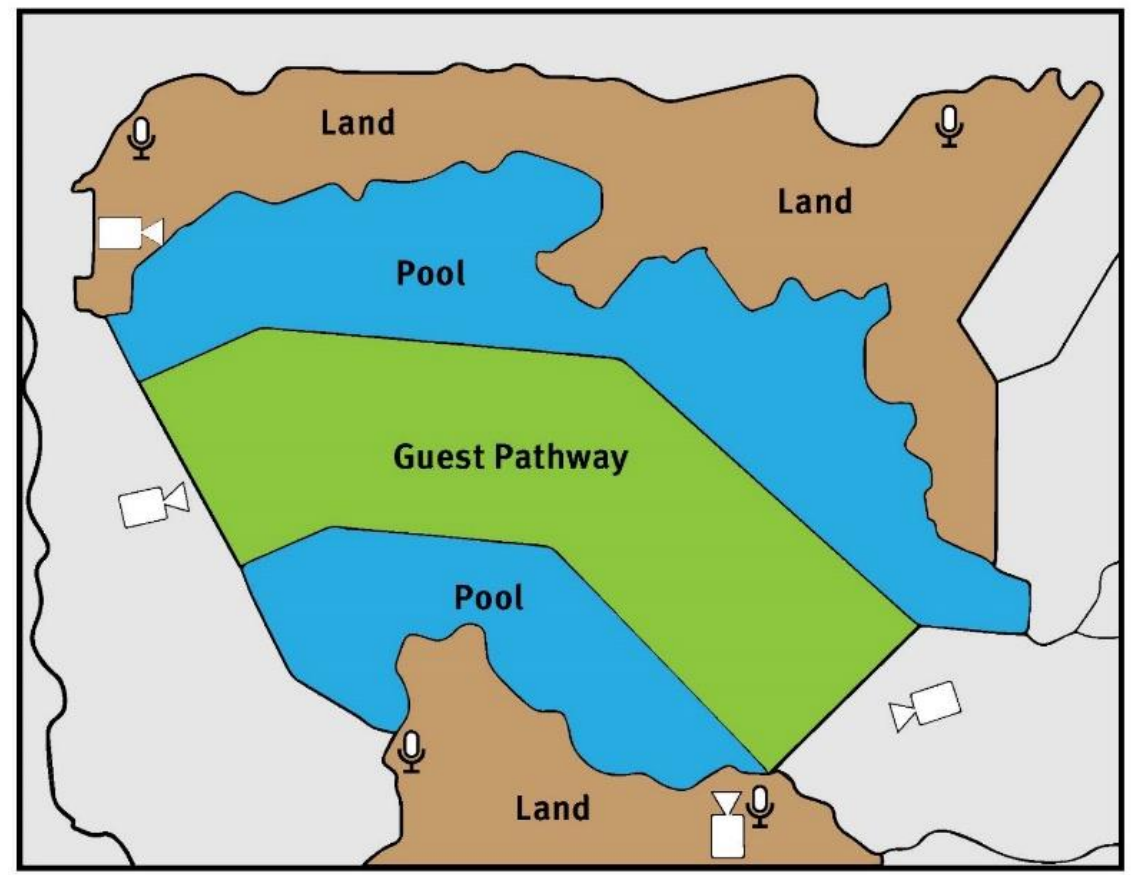

Note. Placement of video and sound recorders identified with camera and microphone icons.

\section{Study Animals}

This mixed-species habitat houses king, gentoo, and southern rockhopper penguins (Table 1). The king and gentoo penguins were all hatched in human care; four southern rockhopper penguins hatched in the wild, with the remaining hatched in human care. As swimming naturally decreases during nesting and molting, we selected a study period when no penguins were molting or nesting so that we could better understand the impact of visitors on swimming without the confound of seasonal variation in behavior. There was no change in husbandry routines during the study. Penguins were tray-fed on land their typical diet of 70\% capelin, 15\% mackerel, $10 \%$ herring, and 5\% smelt twice daily throughout the study. The Saint Louis Zoo's Research Review Committee approved the project.

\section{Table 1}

Sample Characteristics for a Mixed-Species Penguin Colony at the Saint Louis Zoo

\begin{tabular}{cccc}
\hline & King & Gentoo & Southern rockhopper \\
\hline Sample size & 20 & 14 & 24 \\
Males only & 10 & 7 & 11 \\
& & & \\
Age (years) & & & $6-30$ \\
Range & $0.5-28$ & $2-32$ & 17.8 \\
$\bar{x}$ & 13.3 & 17.9 & 6.7 \\
$S D$ & 10.0 & 8.9 & \\
\hline
\end{tabular}




\section{Pool Use and Visitor Data}

Preliminary data were used to determine the placement of four cameras (one IQinVision IQM32N, one Sony IR-2HAD, and two Sanyo VCC-4324) and four sound recording sites (Extech model \#407760) used to monitor penguin pool use, crowd size and composition, and noise levels during the study (see Figure 1). Sound recorders were paired at each of the four sound recording sites $(N=8$ loggers), one recording A-weighted and one recording $\mathrm{C}$-weighted decibel values continuously at oneminute intervals. A-weighted noise scales are rated for the range of hearing in humans and exclude noise at lower frequencies (Ortega, 2012; Pater et al., 2009). However, we also measured in C-weighted scales to detect lower frequency noise, as many animals are able to hear at lower frequencies (Ortega, 2012; Pater et al., 2009). The C-weighted scale also is appropriate for capturing industrial noises such as HVAC systems (Orban et al., 2017), which run continuously in the penguin habitat during summer months to maintain the cooler temperatures needed for these species. To protect the sound loggers from hose spray during keepers' cleaning procedures, each unit was mounted inside of modified baffles made of plastic bottles with the top finish removed to facilitate good reception (Alba, 2015). The sound loggers were removed periodically to download data and then returned the same day after reset and calibration.

Videos were recorded from 09:00 to 15:00 using a network-based recording system. All systems were synchronized with the computer used for sound loggers. Monitoring pool use by specific individuals was not possible due to the difficulty of identifying rapidly swimming penguins (Fuller et al., 2019); therefore, all data were collected at the group level. Every five minutes, scan sampling (Altmann, 1974) was used to record the number of each penguin species on land and in water as well as the number of human adults and children present in the walking path through the habitat. Penguins with any amount of immersion in water were considered as in the pool, whether on the surface, diving, or just entering. As it was possible to see all penguins that were in the pool, out of sight individuals were counted as on land, where multiple hiding spaces were available. The decision to focus on the binary variable of pool use rather than individual behaviors was made due to the number of birds, the visual quality of the cameras, and the difficulty of distinguishing behaviors when birds were in clusters or when in hiding spaces. Of the 2,592 scan samples, 47 were removed due to camera failures prohibiting accurate counts of penguins or guests, resulting in $n=2,545$ data points. One person collected all penguin data; two people with an interobserver reliability agreement of $98 \%$ collected data on crowd size and composition.

\section{Quantitative Analyses}

We calculated the proportion of penguins in the water by species and the proportion of children in the crowd for all scan samples. The noise loggers recorded sound levels in decibels $(\mathrm{dB})$, which is on a logarithmic scale, so for ease of analyses we transformed decibels into untyped sound pressure levels (SPLs) using the formula $10^{[(\mathrm{dB} \text { value)/20]. }}$. Mean sound level in A-weighted and C-weighted scales at each scan sample was determined by averaging data from the four separate noise loggers for that interval. If noise logger failure occurred, averages were calculated using the remaining functional recorders. Before analyzing pool use, we calculated variance inflation factors (VIF) between the visitor effect variables as collinearity between independent variables can affect results. We found no evidence of multicollinearity between crowd size, composition, or noise levels in either scale (VIF $=1.0$ for all pair-wise comparisons). We then assessed visitor effects on each species using linear mixed models with proportion of penguins in the water as the dependent variable and crowd size, composition, and average noise in both A-weighted scale $(\mathrm{dBA})$ and $\mathrm{C}$-weighted scale $(\mathrm{dBC})$ as independent variables. For all three species, we included whether a keeper was in the habitat (yes/no), time of day (AM/PM), and the proportion of penguins in the water for the other two species as fixed effects. As our data were not independent, they were analyzed as a split-plot design by also including day of the study (numbered 1-36) and the interaction of day with time as random effects. We describe results as significant at $p \leq .05$. Analyses were completed in $\mathrm{R}$ ( $\mathrm{R}$ Core 
Team, 2018) with the "usdm" package (Naimi, 2017) for calculating VIFs and the "Ime4" package (Bates et al., 2015) for the linear mixed models.

\section{Results}

Crowd size ranged between $0-51$ guests $(\bar{x}=16.9, \mathrm{SD}=7.98)$ and crowd composition from 0 $100 \%$ children $(\bar{x}=26.0, \mathrm{SD}=14.0)$. Noise levels ranged from 37.6-96.2 dBA $(\bar{x}=78.9, \mathrm{SD}=4.27)$ and from $60.4-95.9 \mathrm{dBC}(\bar{x}=85.5, \mathrm{SD}=2.93)$. The proportion of penguins in the pool at any single scan sample ranged from $0-60 \%(\bar{x}=2.6, \mathrm{SD}=7.60)$ for king penguins, $0-71.4 \%(\bar{x}=11.7, \mathrm{SD}=14.10)$ for gentoo penguins, and $0-41.7 \%(\bar{x}=5.9, \mathrm{SD}=7.20)$ for southern rockhopper penguins.

Relationships between pool use and visitor variables, as well as various fixed effects, varied by species (Table 2). All three species were significantly more likely to be in the water when a keeper was in the habitat. Pool use in king penguins did not significantly vary by crowd size, composition, or noise level in $\mathrm{dBA}$ or $\mathrm{dBC}$. King penguins were significantly more likely to be in the water when gentoo penguins were in the pool, but effects of time of day and the proportion of rockhopper penguins in the pool were not significant. For gentoo penguins, pool use was positively associated with crowd size (Figure 2) but not composition or noise levels in either $\mathrm{dBA}$ or $\mathrm{dBC}$. Gentoo penguins were significantly more likely to engage in pool use during the afternoon and when both king and southern rockhopper penguins were also in the pool. Pool use in southern rockhopper penguins was not significantly associated with crowd size, crowd composition, or noise levels in $\mathrm{dBC}$, but there was a positive effect of noise levels in $\mathrm{dBA}$ on pool use (Figure 3). Finally, southern rockhopper penguins were significantly more likely to engage in pool use during the morning hours and when gentoo penguins were also in the water.

Table 2

Variables Affecting Pool Use in King, Gentoo, and Southern Rockhopper Penguins at the Saint Louis Zoo

\begin{tabular}{|c|c|c|c|c|c|c|c|c|c|}
\hline & \multicolumn{3}{|c|}{ King } & \multicolumn{3}{|c|}{ Gentoo } & \multicolumn{3}{|c|}{ Southern rockhopper } \\
\hline & $\beta$ & SE & $p$ & $\beta$ & SE & $p$ & $\beta$ & SE & $p$ \\
\hline \multicolumn{10}{|l|}{ Independent variables } \\
\hline Crowd size & $<-.001$ & $<0.001$ & .834 & .002 & $<0.001$ & $<.001$ & $<.001$ & $<0.001$ & .207 \\
\hline Crowd composition & $<-.001$ & 0.010 & .969 & -.030 & 0.020 & .138 & .014 & 0.011 & .195 \\
\hline Noise levels (dBA) & $<.001$ & $<0.001$ & .333 & $<.001$ & $<0.001$ & .661 & $<.001$ & $<0.001$ & $<.001$ \\
\hline Noise levels (dBC) & $<-.001$ & $<0.001$ & .076 & $<-.001$ & $<0.001$ & .077 & $<-.001$ & $<0.001$ & .369 \\
\hline \multicolumn{10}{|l|}{ Fixed effects } \\
\hline Keeper in habitat (yes/no) & .024 & 0.004 & $<.001$ & .070 & 0.007 & $<.001$ & .030 & 0.004 & $<.001$ \\
\hline Time (AM/PM) & -.006 & 0.008 & .488 & .034 & 0.013 & .007 & -.027 & 0.006 & $<.001$ \\
\hline King penguins in pool & & & & .393 & 0.040 & $<.001$ & -.006 & 0.022 & .781 \\
\hline Gentoo penguins in pool & .102 & 0.011 & $<.001$ & & & & .058 & 0.011 & $<.0001$ \\
\hline $\begin{array}{l}\text { Southern rockhopper } \\
\text { penguins in pool }\end{array}$ & -.005 & 0.020 & .807 & .210 & 0.039 & $<.001$ & & & \\
\hline
\end{tabular}

Note. dBA - A-weighted decibels; $\mathrm{dBC}$ - C-weighted decibels. Bolded entries indicate significant effects. 
Figure 2

Effects of Crowd Size on Pool Use by Gentoo Penguins

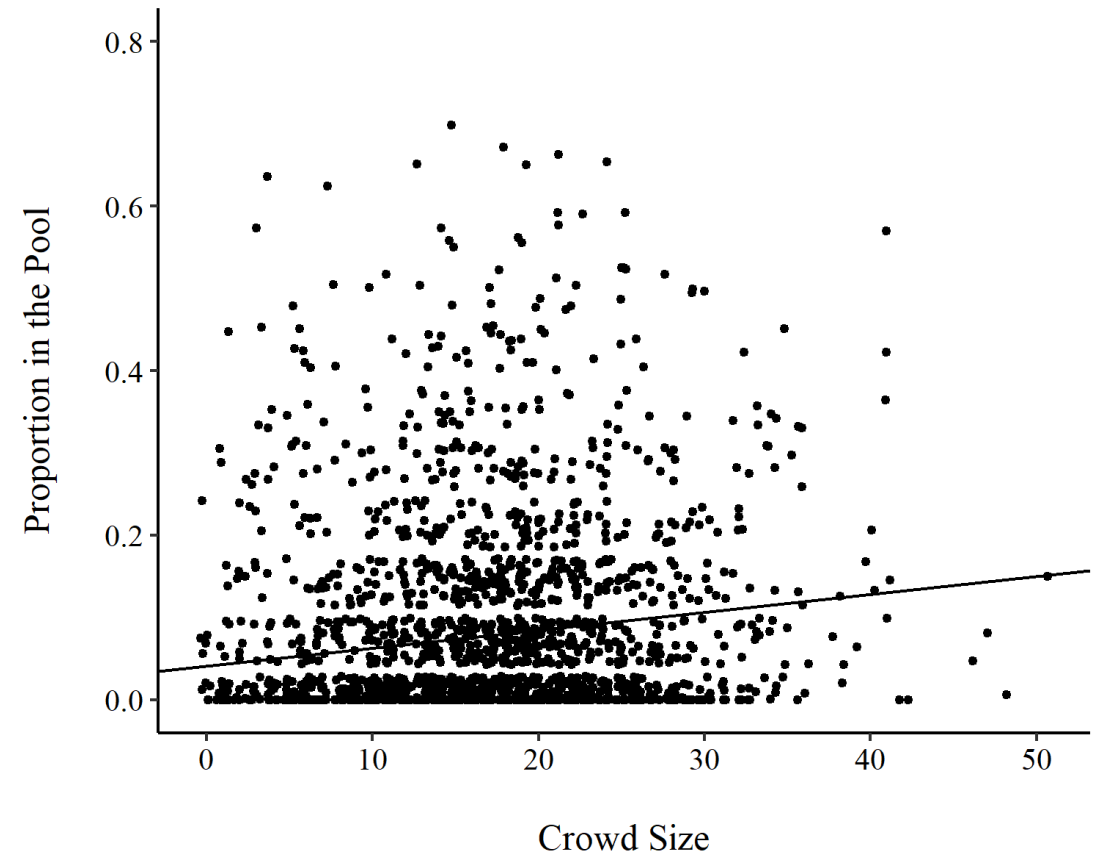

Figure 3

Effects of Average Noise Levels in dBA on Pool Use by Southern Rockhopper Penguins

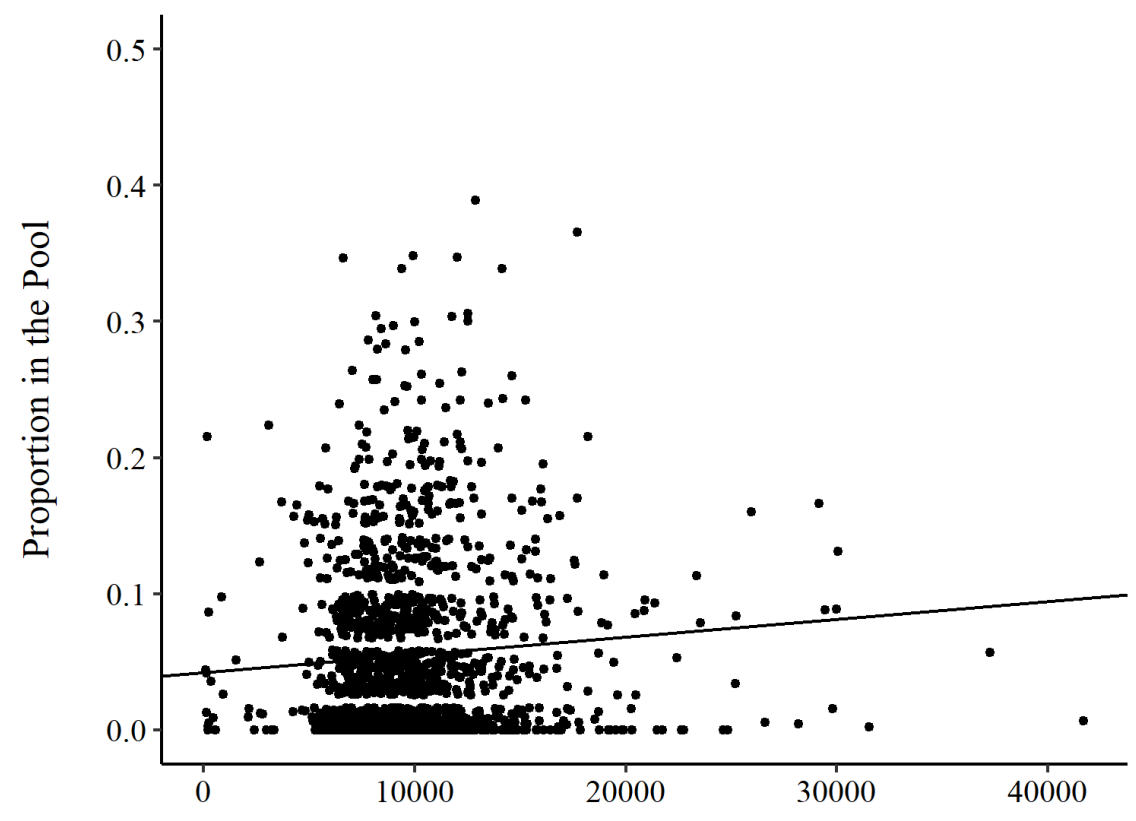

A-weighted Noise Level (SPL) 


\section{Discussion}

Pool use in gentoos significantly increased with larger crowds, but crowd composition did not significantly affect pool use in any species. These results are consistent with studies showing negligible or positive impacts of visitors on African (Brooking \& Price, 2004; Ozella et al., 2017, 2015; Saiyed et al., 2019; Williams et al., 2021), Humboldt (Collins et al., 2019; Condon et al., 2003), gentoo (Brooking \& Price, 2004; Collins et al., 2016, 2019), and Fiordland (Fanning et al., 2020) penguins. Our results are similar to previous research showing gentoo penguins increased frequency of pool behaviors, including surface and underwater swimming, preening in the pool, and porpoising, and behavioral diversity when there were more visitors (Collins et al., 2016). Based on these results, the authors suggested visitors are a positive stimulus to gentoo penguins (Collins et al., 2016).

It is notable that our results contradict studies conducted in little penguins that demonstrated negative impacts of larger crowds on pool use (Chiew et al., 2019; Sherwen et al., 2015), especially since guests could directly approach the pool edge in both cases. Due to the presence of zoo security, visitors may be less likely to perform the behaviors suggested by Chiew and colleagues (2019) to have likely been perceived as threatening by the little penguins, including looming over the wall of the pool, making sudden movements, and reaching for penguins or touching the water. In the wild, heart rate in nesting gentoos recovered quickly when humans approached so long as they did not loom over the birds (Nimon et al., 1995, 1996). In addition to potential differences in guest behavior between studies, the indoor penguin habitat at the Saint Louis Zoo was designed so the lowest land surfaces are at eye level with many adult guests, frequently giving the birds a higher vantage point that may further minimize the perception of visitors as threatening. Birds in a mixed-species aviary found primarily in trees, as opposed to those on the ground, did not retreat from visitor pathways with increases in crowd size (Blanchett et al., 2020). Height relative to visitors may impact other taxa as well, such as primates (Chamove et al., 1988).

Body size also may partially explain the different responses observed here compared to little penguins. Little penguins are the smallest penguin species (Pütz et al., 2013), while king (Bost et al., 2013) and gentoo (Lynch, 2013) penguins are the second and third largest, respectively. Body mass has been proposed to explain differences in intensity of aggression and nest defense between chinstrap and gentoo penguins (Lee et al., 2017). As such, king and gentoo penguins may be less likely to perceive humans as threatening. Southern rockhopper penguins, however, are the second smallest species, larger than only little penguins (Puitz et al., 2013). Given similar body sizes, they might be expected to respond to guests like little penguins do, but pool use in the southern rockhoppers showed no response to crowd size or composition. In this case, social learning may play a role. Both wild and captive penguins show individual variation in responses to humans (Burger \& Gochfeld, 2007; Chiew et al., 2020; Hall et al., 2018; Kalafut \& Kinley, 2020; Lee et al., 2017; Lynch et al., 2019; Saiyed et al., 2019), and it is possible more timid penguins take cues from others on how to respond to visitors. Adélie penguins traveling between nesting sites and the sea have been reported to "clearly influence each other" (Wilson et al., 1991), and birds can learn about predation threats and respond to alarm calls from both conspecifics and heterospecifics (Griffin, 2004; Ortega, 2012). Evolved variation in natural history and temperament also may contribute to species differences in responses to visitors (Claxton, 2011; Sherwen \& Hemsworth, 2019). For example, bird keepers have described little penguins in zoos as highly sensitive whereas other species, such as gentoo and Humboldt penguins, are thought to seek out and enjoy human interaction (F. Fischer and C. Scaggs, personal communication, December 9, 2020).

Noise levels in dBA were positively associated with pool use in southern rockhopper penguins, suggesting louder crowd noise has a positive impact on swimming behavior. Animals are able to habituate to sounds when they learn there is no threat (Pater et al., 2009). Additionally, the presence of zoo security may moderate crowd noise, keeping it within a tolerable range, or the exhibit soundtrack may serve to mask or dampen the crowd noise (Wark, 2015; Wells, 2009). However, it also is possible that loud noises are aversive and southern rockhopper penguins instead engage in pool use as a coping mechanism, reducing noise levels by swimming below the surface. If this is the case, then an aversive 
stimulus may still have a positive impact on welfare through encouraging species-typical activity. Additionally, the penguins themselves are responsible for a substantial amount of noise. Wild penguins live in noisy colonies (e.g., over $70 \mathrm{dBC}$ for king and emperor penguins; Aubin \& Jouventin, 1998; Jouventin et al., 1999). Although mean noise levels for both scales in this study exceeded the ambient noise reported in the wild, noise levels during the pilot study provide insight into "baseline" colony noise. Pilot study noise levels ranged from 66.7-81.5 dBA ( $\bar{x}=70.7, \mathrm{SD}=3.20 ; \mathrm{dBC}$ values unavailable $)$, which is aligned with those observed in wild penguin colonies.

In addition to species differences in responses to visitors, we also observed significant associations between pool use and multiple fixed effects included in our models. First, all three species were more likely to engage in pool use when a keeper was in the habitat. Given that the penguins readily approached keepers at feeding times, the association here is more likely due to the animals moving out of the way during cleaning procedures rather than avoidance behavior due to aversion or fear. Time of day also significantly influenced pool use in gentoo and southern rockhopper penguins, but the associations may not be biologically meaningful. While differences in preferred swimming times could reflect niche partitioning in a mixed-species colony, the absolute differences between the proportion in the water by time of day are minimal and not equivalent to one individual for either species. Finally, the proportion of penguins swimming was influenced by other species in the pool. Pool use by gentoo penguins was positively associated with pool use by both king and southern rockhopper penguins, although these latter two did not significantly influence one another. As gentoo penguins swim more with larger crowds, the positive associations with pool use by the other two species further support the suggestion that penguins in this colony overall do not find humans aversive and that social cues may help moderate individual responses. Alternatively, as we do not know the direction of the relationship observed here, it is possible some penguins felt safer swimming near guests when in larger groups; penguins form groups at sea to reduce risk of predation (Mori, 1999).

As pool use is widely considered to promote positive welfare, our findings suggest visitors do not negatively impact the welfare of penguins in this mixed-species colony and may actually enhance welfare for some species. However, it is important to consider the possibility that pool use, while promoting positive welfare from natural living (e.g., performing species-typical behaviors) and biological functioning (e.g., physical activity and health) perspectives (Browning, 2020; Fraser, 2009), does not represent positive affective states in penguins. While swimming is a highly motivated behavior, in the wild this motivation likely stems from hunger, a negative affective state. With their dietary needs accounted for, zoo-housed penguins may instead choose to swim because they enjoy doing so. For example, keepers at Penguin and Puffin Coast anecdotally report that the penguins often use the pool to move around even when walking over land is an option (C. Scaggs, personal communication, December 9, 2020). It also is possible penguins instead enter the pool as an evasive maneuver, as they are faster in the water. For example, a swimming behavior known as porpoising is the fastest mode of locomotion for penguins and can be used in the wild to escape predators (Luna-Jorquera \& Culik, 1999; Randall \& Randall, 1990). Improving our understanding of what motivates penguins to swim in captivity is important for promoting positive animal welfare. Until we better understand swimming motivation in penguins, it would be beneficial to include other potential indicators of positive welfare, such as detailed behavior and enclosure use, interactions with enrichment, or physiological measures, to gain a more holistic perspective.

Unfortunately, due to the size of the habitat and placement of our cameras, we could not consistently distinguish on video the different types of behavior that are sometimes monitored in penguins to better understand their affective or motivational state. For example, penguins that find visitors stimulating may engage in more preening or stretching, while those that find guests aversive may spend more time huddling or immobile (Chiew et al., 2019, 2020). Collecting data at the group- rather than individual-level prevents us from determining if these results characterize all members of the group or if there were specific traits, such as temperament or past history, affecting individual responses. Importantly, any penguins that find guests aversive have the choice to remain out of sight in this habitat, 
although being out of sight while swimming is not a viable option; the only time penguins are out of view while swimming is when they pass beneath the walkway to enter the other side of the pool. The provision of hiding spaces has been shown to improve welfare in other taxa (e.g., clouded leopards, Wielebnowski et al., 2002; Fennec foxes, Carlstead, 1991; African clawed frogs, Chum et al., 2013). Being able to exercise choice and control over some aspects of the environment is essential to good animal welfare (Brando \& Buchanan-Smith, 2018; Broom, 1988; Hill \& Broom, 2009; Meehan \& Mench, 2007; Whitham \& Wielebnowski, 2013). Seasonality also impacts penguin swimming behaviors and as such, these results may not generalize to other time periods. For example, during nesting season or when chicks are dependent on their parents, penguins may be naturally less likely to swim and/or more sensitive to stimuli from visitors.

Previous studies on the effects of visitors on pool use and other behaviors in zoo-housed penguins have shown mixed results. We investigated whether penguins housed in a mixed-species colony in human care change their pool use in response to crowd size, crowd composition, and noise levels. As this is an indoor habitat, it is unlikely that these results can be explained by the visitor attraction hypothesis (i.e., higher visitor counts at exhibits being due to animals performing active behaviors and attracting guest attention; Hosey, 2000, 2008). Instead, these results suggest guests have a neutral impact on king penguins but stimulate pool use in gentoo and southern rockhopper penguins, which may have positive impacts on welfare. Given the diversity of natural histories across this taxonomic group and the results from this study, it is unlikely all penguin species perceive humans the same way and effects of visitors may be further complicated by within-species variation. As such, future work exploring how temperament, social learning, and species interactions shape responses to guests would be beneficial, as it may be possible to ameliorate potentially negative impacts of guests for more vulnerable individuals and species via carefully planned mixed-species housing. For penguin species and individuals that may benefit from visitors, habitat designs that place pools near visitor viewing areas and pathways likely contribute to their welfare by helping encourage species-typical locomotion as they seek out interactions with guests.

\section{Acknowledgments}

The authors thank the team of animal care staff at Penguin and Puffin Coast and in the entire Bird Department for their assistance with this project. We also thank Theodore G. Meyer for his assistance streamlining our data analysis processes and Dr. Susan Meiers at Western Illinois University for insight into project development. The authors also thank the editor and three anonymous reviewers for their comments to improve this manuscript.

\section{References}

Alba, A. C. (2015). Captive management, stress, and reproduction in the Guam kingfisher [unpublished Master's thesis]. University of Missouri-Columbia.

Altmann, J. (1974). Observational study of behavior: Sampling methods. Behaviour, 49, 227-267.

Aubin, T., \& Jouventin, P. (1998). Cocktail-party effect in king penguin colonies. Proceedings of the Royal Society $B, 265,1665-1673$.

Azevedo, C. S. de, Lima, M. F. F., Silva, V. C. A. da, Young, R. J., \& Rodrigues, M. (2012). Visitor influence on the behavior of captive greater rheas (Rhea americana, Rheidae Aves). Journal of Applied Animal Welfare Science, 15(2), 113-125.

Barbosa, A., de Mas, E., Benzal, J., Diaz, J. I., Motas, M., Jerez, S., Pertierra, L., Benayas, J., Justel, A., Lauzurica, P., Garcia-Peña, F. J., \& Serrano, T. (2013). Pollution and physiological variability in gentoo penguins at two rookeries with different levels of human visitation. Antarctic Science, 25(2), 329-338.

Bates, D., Maechler, M., Bolker, B., Walker, S., Christensen, R. H. B., Singmann, H., Dai, B., Scheipl, F., Grothendieck, G., Green, P., \& Fox, J. (2015). lme4: Linear mixed-effects models using "Eigen” and S4 (R package version 1.1-19) [Computer software]. https://cran.r-project.org/package=lme4 
Blanchett, M. K. S., Finegan, E., \& Atkinson, J. (2020). The effects of increasing visitor and noise levels on birds within a free-flight aviary examined through enclosure use and behavior. Animal Behavior and Cognition, 7(1), 49-69.

Bost, C.-A., Delord, K., Barbraud, C., Cherel, Y., Pütz, K., Péron, C., \& Weimerskirch, H. (2013). King penguin (Aptenodytes patagonicus). In P. G. Borboroglu \& P. D. Boersma (Eds.), Penguins natural history and conservation (pp. 7-21). Washington University Press.

Brando, S., \& Buchanan-Smith, H. M. (2018). The 24/7 approach to promoting optimal welfare for captive wild animals. Behavioural Processes, 156, 83-95.

Brooking, Z. A., \& Price, D. J. (2004). The effect of human presence on the behavioural and distributional patterns of two species of captive penguins, African (Spheniscus demersus) and gentoo (Pygoscelis papua), on being transferred into their new enclosure at Living Coasts, Devon. Proceedings of the 6th Annual Symposium on Zoo Research, 170-179. British and Irish Association of Zoos and Aquariums, London, England.

Broom, D. R. (1988). The scientific assessment of animal welfare. Applied Animal Behaviour Science, 20(1-2), 519.

Browning, H. (2020). The natural behavior debate: Two conceptions of animal welfare. Journal of Applied Animal Welfare Science, 23(3), 325-337.

Burger, J., \& Gochfeld, M. (2007). Responses of emperor penguins (Aptenodytes forsteri) to encounters with ecotourists while commuting to and from their breeding colony. Polar Biology, 30(10), 1303-1313.

Carlstead, K. (1991). Husbandry of the Fennec fox Fennecus zerda: Environmental conditions influencing stereotypic behavior. International Zoo Yearbook, 30, 202-207.

Chamove, A. S., Hosey, G., \& Schaetzel, P. (1988). Visitors excite primates in zoos. Zoo Biology, 7(4), 359-369.

Chiew, S. J., Butler, K. L., Sherwen, S. L., Coleman, G. J., Fanson, K. V., \& Hemsworth, P. H. (2019). Effects of regulating visitor viewing proximity and the intensity of visitor behaviour on Little Penguin (Eudyptula minor) behaviour and welfare. Animals, 9(6), 285.

Chiew, S. J., Butler, K. L., Sherwen, S. L., Coleman, G. J., Melfi, V., Burns, A., \& Hemsworth, P. H. (2020). Effect of covering a visitor viewing area window on the behaviour of zoo-housed little penguins (Eudyptula minor). Animals, 10(7), 1224.

Chum, H., Felt, S., Garner, J., \& Green, S. (2013). Biology, behavior, and environmental enrichment for the captive African clawed frog (Xenopus spp). Applied Animal Behaviour Science, 143(2), 150-156.

Claxton, A. M. (2011). The potential of the human-animal relationship as an environmental enrichment for the welfare of zoo-housed animals. Applied Animal Behaviour Science, 133(1), 1-10.

Cobley, N. D., \& Shears, J. R. (1999). Breeding performance of gentoo penguins (Pygoscelis papua) at a colony exposed to high levels of human disturbance. Polar Biology, 21(6), 355-360.

Collins, C. K., \& Marples, N. M. (2015). Zoo playgrounds: A source of enrichment or stress for a group of nearby cockatoos? A case study. Journal of Applied Animal Welfare Science, 18(4), 375-387.

Collins, C., Quirke, T., McKeown, S., Flannery, K., Kennedy, D., \& O’Riordan, R. (2019). Zoological education: Can it change behaviour? Applied Animal Behaviour Science, 220, 104857.

Collins, C., Quirke, T., Overy, L., Flannery, K., \& O'Riordan, R. (2016). The effect of the zoo setting on the behavioural diversity of captive gentoo penguins and the implications for their educational potential. Journal of Zoo and Aquarium Research, 4(2), 85-90.

Condon, E., Wehnelt, S., \& Turner, Z. (2003). The effect of visitors on the behaviour of Humboldt penguins at Chester Zoo. Zoo Federation Research Newsletter, 4(2), 3.

Davey, G. (2007). Visitors' effects on the welfare of animals in the zoo: A review. Journal of Applied Animal Welfare Science, 10, 169-183.

Downes, K. J. (2012). Is there a visitor effect on behaviour and enclosure use of mixed bird species in a zoo enclosure. The Plymouth Student Scientist, 5(1), 38-60.

Ellenberg, U., Mattern, T., Houston, D. M., Davis, L. S., \& Seddon, P. J. (2012). Previous experiences with humans affect responses of snares penguins to experimental disturbance. Journal of Ornithology, 153(3), 621-631.

Ellenberg, U., Mattern, T., \& Seddon, P. J. (2009). Habituation potential of yellow-eyed penguins depends on sex, character and previous experience with humans. Animal Behaviour, 77(2), 289-296.

Ellenberg, U., Mattern, T., Seddon, P. J., \& Jorquera, G. L. (2006). Physiological and reproductive consequences of human disturbance in Humboldt penguins: The need for species-specific visitor management. Biological Conservation, 133(1), 95-106. 
Ellenberg, U., Setiawan, A. N., Cree, A., Houston, D. M., \& Seddon, P. J. (2007). Elevated hormonal stress response and reduced reproductive output in yellow-eyed penguins exposed to unregulated tourism. General and Comparative Endocrinology, 152(1), 54-63.

Erlacher-Reid, C., Dunn, J. L., Camp, T., Macha, L., Mazzaro, L., \& Tuttle, A. D. (2012). Evaluation of potential variables contributing to the development and duration of plantar lesions in a population of aquariummaintained African penguins (Spheniscus demersus). Zoo Biology, 31(3), 291-305.

Fanning, L., Larsen, H., \& Taylor, P. S. (2020). A preliminary study investigating the impact of musical concerts on the behavior of captive Fiordland penguins (Eudyptes pachyrhynchus) and collared peccaries (Pecari tajacu). Animals, 10(11), 2035.

Fernandez, E. J., Kinley, R. C., \& Timberlake, W. (2019). Training penguins to interact with enrichment devices for lasting effects. Zoo Biology, 38(6), 481-489.

Fernandez, E. J., Myers, M., \& Hawkes, N. C. (2021). The effects of live feeding on swimming activity and exhibit use in zoo Humboldt penguins (Spheniscus humboldti). Journal of Zoological and Botanical Gardens, 2(1), $88-100$.

Fernandez, E. J., Tamborski, M. A., Pickens, S. R., \& Timberlake, W. (2009). Animal-visitor interactions in the modern zoo: Conflicts and interventions. Applied Animal Behaviour Science, 120(1), 1-8.

Fowler, G. S. (1999). Behavioral and hormonal responses of Magellanic penguins (Spheniscus magellanicus) to tourism and nest site visitation. Biological Conservation, 90, 143-149.

Francis, C. D., Ortega, C. P., \& Cruz, A. (2009). Noise pollution changes avian communities and species interactions. Current Biology, 19(16), 1415-1419.

Fraser, D. (2009). Assessing animal welfare: Different philosophies, different scientific approaches. Zoo Biology, 28(6), 507-518.

Fuller, G., Heintz, M. R., \& Allard, S. (2019). Validation and welfare assessment of flipper-mounted time-depth recorders for monitoring penguins in zoos and aquariums. Applied Animal Behaviour Science, 212, 114122.

Griffin, A. S. (2004). Social learning about predators: A review and prospectus. Learning \& Behavior, 32(1), 131140 .

Hall, B. A., Melfi, V., Burns, A., McGill, D. M., \& Doyle, R. E. (2018). Curious creatures: A multi-taxa investigation of responses to novelty in a zoo environment. PeerJ, 6, e4454.

Hill, S. P., \& Broom, D. M. (2009). Measuring zoo animal welfare: Theory and practice. Zoo Biology, 28, 531-544.

Holmes, N. D. (2007). Comparing king, gentoo, and royal penguin response to pedestrian visitation. The Journal of Wildlife Management, 71(8), 2575-2582.

Holmes, N. D., Giese, M., Achurch, H., Robinson, S., \& Kriwoken, L. K. (2006). Behaviour and breeding success of gentoo penguins Pygoscelis papua in areas of low and high human activity. Polar Biology, 29(5), 399-412.

Hosey, G. R. (2000). Zoo animals and their human audiences: What is the visitor effect? Animal Welfare, 9, 343357.

Hosey, G. R. (2005). How does the zoo environment affect the behaviour of captive primates? Applied Animal Behaviour Science, 90, 107-129.

Hosey, G. R. (2008). A preliminary model of human-animal relationships in the zoo. Applied Animal Behaviour Science, 109(2), 105-127.

Jouventin, P., Aubin, T., \& Lengagne, T. (1999). Finding a parent in a king penguin colony: The acoustic system of individual recognition. Animal Behaviour, 57(6), 1175-1183.

Jouventin, P., \& Aubin, T. (2002). Acoustic systems are adapted to breeding ecologies: Individual recognition in nesting penguins. Animal Behaviour, 64(5), 747-757.

Kalafut, K. L., \& Kinley, R. (2020). Using radio frequency identification for behavioral monitoring in little blue penguins. Journal of Applied Animal Welfare Science, 23(1), 62-73.

Lee, W. Y., Jung, J.-W., Choi, H.-G., Chung, H., Han, Y.-D., Cho, S.-R., \& Kim, J.-H. (2017). Behavioral responses of chinstrap and gentoo penguins to a stuffed skua and human nest intruders. Polar Biology, 40(3), 615624.

Luna-Jorquera, G., \& Culik, B. M. (1999). Diving behaviour of Humboldt penguins Spheniscus humboldti in Northern Chile. Marine Ornithology, 27, 67-76.

Lynch, H. J. (2013). Gentoo penguin (Pygoscelis papua). In P. G. Borboroglu \& P. D. Boersma (Eds.), Penguin natural history and conservation. (pp. 73-88). Washington University Press.

Lynch, M. A., Youngflesh, C., Agha, N. H., Ottinger, M. A., \& Lynch, H. J. (2019). Tourism and stress hormone measures in gentoo penguins on the Antarctic Peninsula. Polar Biology, 42(7), 1299-1306. 
Marshall, A. R., Deere, N. J., Little, H. A., Snipp, R., Goulder, J., \& Mayer-Clarke, S. (2016). Husbandry and enclosure influences on penguin behavior and conservation breeding. Zoo Biology, 35(5), 385-397.

Meehan, C. L., \& Mench, J. A. (2007). The challenge of challenge: Can problem solving opportunities enhance animal welfare? Applied Animal Behaviour Science, 102(3), 246-261.

Mori, Y. (1999). A note on swimming group size in captive African penguins (Spheniscus demersus) in relation to weather conditions. Applied Animal Behaviour Science, 62(4), 359-364.

Naimi, B. (2017). usdm: Uncertainty analysis for species distribution models (R package version 1.1-18). https://cran.r-project.org/package $=$ usdm

Nimon, A. J., \& Dalziel, F. R. (1992). Cross-species interaction and communication: A study method applied to captive siamang (Hylobates syndactylus) and long-billed corella (Cacatua tenuirostris) contacts with humans. Applied Animal Behaviour Science, 33, 261-272.

Nimon, A. J., Schroter, R. C., \& Oxenham, R. K. (1996). Artificial eggs: Measuring heart rate and effects of disturbance in nesting penguins. Physiology \& Behavior, 60(3), 1019-1022.

Nimon, A. J., Schroter, R. C., \& Stonehouse, B. (1995). Heart rate of disturbed penguins. Nature, $374,415$.

Orban, D. A., Soltis, J., Perkins, L., \& Mellen, J. D. (2017). Sound at the zoo: Using animal monitoring, sound measurement, and noise reduction in zoo animal management. Zoo Biology, 36(3), 231-236.

Ortega, C. P. (2012). Effects of noise pollution on birds: A brief review of our knowledge. Ornithological Monographs, 74, 6-22.

Ozella, L., Anfossi, L., Di Nardo, F., \& Pessani, D. (2017). Effect of weather conditions and presence of visitors on adrenocortical activity in captive African penguins (Spheniscus demersus). General and Comparative Endocrinology, 242, 49-58.

Ozella, L., Favaro, L., Carnovale, I., \& Pessani, D. (2015). Pond use by captive African penguins (Spheniscus demersus) in an immersive exhibit adjacent to human bathers. Journal of Applied Animal Welfare Science, 18(3), 303-309.

Pater, L. L., Grubb, T. G., \& Delaney, D. K. (2009). Recommendations for improved assessment of noise impacts on wildlife. Wildfire, 73(5), 788-795.

Pelletier, C., Weladji, R. B., Lazure, L., \& Paré, P. (2020). Zoo soundscape: Daily variation of low-to-highfrequency sounds. Zoo Biology, 39(6), 374-381.

Pütz, K., Rey, A. R., \& Otley, H. (2013). Southern rockhopper penguin (Eudyptes chrysocome). In P. G. Borboroglu \& P. D. Boersma (Eds.), Penguin natural history and conservation. Washington University Press.

R Core Team. (2018). R: A language and environment for statistical computing. [Computer software]. R Foundation for Statistical Computing. https://www.R-project.org

Randall, R. M., \& Randall, B. M. (1990). Cetaceans as predators of jackass penguins Spheniscus demersus: Deductions based on behaviour. Marine Ornithology, 18, 9-12.

Rose, P. E., Brereton, J. E., \& Croft, D. P. (2018). Measuring welfare in captive flamingos: Activity patterns and exhibit usage in zoo-housed birds. Applied Animal Behaviour Science, 205, 115-125.

Rose, P. E., Scales, J. S., \& Brereton, J. E. (2020). Why the "visitor effect" is complicated. Unraveling individual animal, visitor number, and climatic influences on behavior, space use and interactions with keepers-a case study on captive hornbills. Frontiers in Veterinary Science, 7, 236.

Saiyed, S. T., Hopper, L. M., \& Cronin, K. A. (2019). Evaluating the behavior and temperament of African penguins in a non-contact animal encounter program. Animals, 9(6), 326.

Sherwen, S. L., \& Hemsworth, P. H. (2019). The visitor effect on zoo animals: Implications and opportunities for zoo animal welfare. Animals, 9(6), 366.

Sherwen, S. L., Magrath, M. J. L., Butler, K. L., \& Hemsworth, P. H. (2015). Little penguins, Eudyptula minor, show increased avoidance, aggression and vigilance in response to zoo visitors. Applied Animal Behaviour Science, 168, 71-76.

Simeone, A., Wilson, R. P., Knauf, G., Knauf, W., \& Schützendübe, J. (2002). Effects of attached data-loggers on the activity budgets of captive Humboldt penguins: Effects of data-loggers on captive penguins. Zoo Biology, 21(4), 365-373.

Terio, K. A., Mcaloose, D., \& St. Leger, J. (2018). Pathology of wildlife and zoo animals. Academic Press.

van Heezik, Y., \& Seddon, P. J. (1990). Effect of human disturbance on beach groups of jackass penguins. South African Journal of Wildlife Research, 20(3), 89-93.

Vargas-Ashby, H. E., \& Pankhurst, S. J. (2007). Effects of feeding enrichment on the behaviour and welfare of captive Waldrapps (Northern bald ibis) (Geronticus eremita). Animal Welfare, 16, 369-374. 
Viblanc, V. A., Smith, A. D., Gineste, B., \& Groscolas, R. (2012). Coping with continuous human disturbance in the wild: Insights from penguin heart rate response to various stressors. BMC Ecology, 12, 10.

Walker, B. G., Boersma, P. D., \& Wingfield, J. C. (2005). Physiological and behavioral differences in Magellanic penguin chicks in undisturbed and tourist-visited locations of a colony. Conservation Biology, 19(5), 15711577.

Walker, B. G., Boersma, P. D., \& Wingfield, J. C. (2006). Habituation of adult Magellanic penguins to human visitation as expressed through behavior and corticosterone secretion. Conservation Biology: The Journal of the Society for Conservation Biology, 20(1), 146-154.

Wark, J. D. (2015). The influence of the sound environment on the welfare of zoo-housed callitrichine monkeys [unpublished doctoral dissertation]. Case Western Reserve University.

Warren, I., Parry, L., Cuthill, I., \& Barham, P. (2003). The effects of human disturbance on captive African (Spheniscus demersus) and gentoo (Pygoscelis papua) penguins. Proceedings of the 4th Annual Symposium on Zoo Research. Federation of Zoological Gardens of Great Britain and Ireland, London, England.

Wells, D. L. (2009). Sensory stimulation as environmental enrichment for captive animals: A review. Applied Animal Behaviour Science, 118(1), 1-11.

Whitham, J. C., \& Wielebnowski, N. (2013). New directions for zoo animal welfare science. Applied Animal Behaviour Science, 147(3), 247-260.

Wielebnowski, N. C., Fletchall, N., Carlstead, K., Busso, J. M., \& Brown, J. L. (2002). Noninvasive assessment of adrenal activity associated with husbandry and behavioral factors in the North American clouded leopard population. Zoo Biology, 21(1), 77-98.

Williams, E., Carter, A., Rendle, J., \& Ward, S. J. (2021). Understanding impacts of zoo visitors: Quantifying behavioural changes of two popular zoo species during COVID-19 closures. Applied Animal Behaviour Science, 236, 105253.

Wilson, R. P., Culik, B., Danfeld, R., \& Adelung, D. (1991). People in Antarctica - How much do adélie penguins Pygoscelis adeliae care? Polar Biology, 11, 363-370. 